\title{
On Li Dazhao's Critical Inheritance of Chinese Traditional Culture
}

\begin{abstract}
Zhou $\mathrm{Yu}^{1}$
${ }^{1}$ Shanghai Institute of Technology, Shanghai,201418, China

fudzhy@163.com

ABSTRACT

Li Dazhao, an outstanding representative of early Marxists, based on the traditional Chinese culture, actively explored and applied the position, viewpoint and method of Marxism, forming a representative traditional cultural view. In the process of criticizing and inheriting, respecting and interpreting Chinese traditional culture, Li Dazhao explored the main idea of integrating Marxist historical materialism into Confucianism, used modern democratic political theory to transform the traditional Chinese theory of "people and Yi", combined the Confucian theory of "good nature" and Taoist theory of "Inaction" with the criticism of modern autocratic system, and put Marxism into practice The combination of political economy and its thought of "Populism", the pursuit of Marxist revolutionary heroism and other ideas based on the optimistic outlook on life in traditional Chinese culture, the dialectical and systematic excavation of the modern value of traditional Chinese culture for future generations, the establishment of cultural self-confidence, and the promotion of the combination of excellent traditional Chinese culture and contemporary Marxism are of great enlightenment meaning.
\end{abstract}

Keywords: Li Dazhao, traditional culture, Marxism

\section{论李大钊对中国传统文化的批判性继承}

周妤 1

\author{
1 上海应用技术大学 上海 中国 201418 \\ fudzhy@163.com
}

\begin{abstract}
摘要
早期马克思主义者的杰出代表人物李大钊，立足于中国传统文化，积极探索运用马克思主义的立场、观点和方 法,形成了具有代表性意义上的传统文化观。在对中国传统文化批判与继承、尊重与解读的推陈出新的过程中, 李大钊探讨马克思主义唯物史观融入儒家思想的主旨，运用现代民主政治学说改造中国传统意义上的 “民彝” 学说，将儒家“性善论”和道家 “无为” 论与批判现代专制制度结合考量，将马克思主义政治经济学与其 “平民 主义” 思想相结合，倡导以中国传统文化中的乐观主义人生观为基础追求马克思主义的革命英雄主义等思路， 为后人辩证系统地挖掘中国传统文化的现代价值, 树立文化自信, 推进中华优秀传统文化与当代马克思主义相 结合, 都具有重要的启迪意义。
\end{abstract}

关键词: 李大钐, 传统文化, 马克思主义

\section{1. 前言}

早期马克思主义者是中国近现代知识分子的一 个具有鲜明特点的群体。他们在近现代中国西学东渐 的大环境之下，无法回避对待古今中西文化的态度。 这个态度决定了他们秉承中国传统知识分子 “治国平 天下” 的 “入世” 哲学和方法。其中杰出的代表人物 李大钊 (1889-1927) 对待传统文化的态度客观而理性,
抽象而务实。他倡导将现代文明的先进性与传统文化 中积极性结合, 尤其是他运用现代文明的话语体系解 读传统文化中深层次因素的思想方法, 值得终结并发 扬光大。 


\section{2. 李大钊运用马克思主义唯物史观为指导 反思了以孔子为代表的儒家学说}

李大钊 “幼时在乡村私校,曾读四书经史,年十六, 应科举试”。[1]儒家 “修齐治平” 的理想必然会对其人 生目标产生影响。但随着李大钊社会见识的扩大和知 识结构的丰富, 他能够理性地对中国传统文化中不适 应时代要求的落后、腐朽的观念进行了批判与反思。 他反对宪法草案将孔子之道确立为国民教育修身的 大本。因为 “数千年前之残骸枯骨” 和 “历代帝王专 制之护符” 是落后、腐朽的封建残余, 与现代宪法精 神不能兼容。与此同时, 李大钊对孔子的认知态度又 是历史的、客观的，一分为二的。他认为孔子之道符合 真理的部分是人类共同智慧。他说: “余信宇宙间有 惟一无二之真理。此真理者, 乃宇宙之本体, 非一人 一教所得而私也。” ${ }^{[2]}$

李大钊倡导抛弃传统文化中拘泥于先哲贤人思 维定势的局限性, 挖掘传统文化中富有生气的元素, 将个性彰显与现实社会变革相结合。他儒家文化及其 代表人物孔子的学说是随着历史的演进而不断进步 的, 经过了实在型态、历史型态和世界型态的历史演 进, 后人在传承过程中要具体分析。他视实在型态下 的孔子为圣哲, 认为儒家学说是宇宙天地间的 “惟一 无二之真理”。他视历史型态下的神圣化的孔子是君 主专制的工具, 中国人的当务之急就是要破除儒家学 说中的固疾。同时, 李大钊是世界型态下的孔子是中 国文化自信、民族自豪的标杆。因为孔子是世界四大 圣哲之一, 是东亚文化乃至世界文化的最高典范, 是 中华民族文化的象征, 必须加以维护和发扬光大。可 见, 李大钊理性地在总结历史文化经验的同时上, 也 完成了自我的文化反思。

李大钊在接受马克思主义之后, 自觉地运用唯物 史观进一步反思了孔门思想。他认为以孔子为代表的 三纲五常的伦理道德、“修齐治平” 的政治哲学、“一 以贯之” 的自律规范都有约束人的个性发展的局限性。 这些局限性必将在西方文化的冲击之下开始动摇。他 认为从本质上看, 既然大家族制度已经步入了崩颓粉 碎的命运, 孔子主义也就会随之而崩颓粉碎。因此, 中 国今日种种思想解放运动无一不是打破孔子主义的 运动。

\section{3. 李大钊运用现代民主政治学说赋予了中 国传统意义上的 “民彝” 论以民主主义的新 内涵}

李大钊将传统意义上的“民彝”观赋予了具有现 代民主政治含义。传统“民彝”的基本含义是风俗和伦 常, 包括了道与器、体与用、实与虚的多重逻辑。他 说: “然则民彝者, 悬于智照则为形上之道, 应于事物 则为形下之器, 虚之则为心理之澂, 实之则为逻辑之 用也。” [3]李大钊还认为, 具有至善元素的“天理”决定 “人性”, 因此人性的发展趋势是“至善而止”。基于此,
李大钊揭示了“民彝”在社会历史的过程中“趋于至善 而止”的规律。也就是说，在“民彝”的思维系统里面， 存在着能够被认知的形而上的“道”和“体”, 能够被运 用的形而下的“器”和“用”, 能够被掌握的“虚”与“实” 共生逻辑思维方法。这就意味着, 人的行为规范和思 维方式必须受到“性善”的价值尺度约束, 发挥人的创 造性, 以便在日常伦理和现实政治中达成“至善而止” 的境界。

李大钊以 “民彝” 政治理论作为批判北洋政府复辟 帝制, 呼吁民主共和的政治神器。他说: “《民彝》何 为而作也? 大盗窃国, 予智自雄, 凭藉政治之枢机, 战 贼风俗之大本。” ${ }^{[4]}$ 随着时代的发展, 作为政治神器的象 征物已经由古代的可以窃取民权的 “宗彝” 转变为现 代不可窃取的 “民彝”，强调了现代 “民彝” 政治的必然 性和合理性。李大钊还揭露了君主专制是国家和人民苦 难的根源, 君主专制与民主共和不能共生的格局。这是 因为, 在现代社会, 必然会出现民与君势不两立, 自由 与专制不能并存的局面。

李大钊还提出了 “常” 的概念。如果说 “器” 是一 种政治工具, 那么 “常” 就是一种政治原则, 或者说政 治立场。他将道家 “无为” 融合到 “常” 的概念之中, 从 “常” 的角度来理解 “民彝” ，接受 “顺民彝自然之 演进” 之常态, 之规律。其目的就是弱化社会教化意义 上的 “民德” 思想, 强化从现实政治原则出发, 来施行 惠及民众的政策。因为 “为治之道不尚振奇幽远之理, 但求平易近人，以布帛菽粟之常，与众共由”。 ${ }^{\left[{ }^{5}\right]}$ 民众 的衣食住行是民情的一面镜子, 要解决中国的问题, 实 现社会稳定, 必须立足于中国国情, 切忌使用以开明之 条教, 来衡量无组织的民众; 依有方之典刑, 约束无方 之群众的方法。

李大钊视民彝为是民宪之基础, 因此 “法” 既是现 代国家的法律法规，又是“民彝”发展而成的政治制度。 既然 “民彝” 是民主宪政的坚持, 那么追求民主主义就 是一条改造人类社会的光明大道。具体而言就是“惟民 主义为其精神、代议制度为其形质之政治, 易词表之, 即国法与民彝间之联络愈益疏通之政治也。”[6]他强烈呼 叮中国人要秉持 “民彝” 的理念, 以一些先进国家追求 民主的精神为比照, 克服封建专制主义的艰难险阻, 将 寻求具有法律保障的现代民主主义的光明前景作为唯 一天职。

\section{4. 李大钊将中国传统文化的多元因素与现 代民主政治理论相结合}

李大钊将儒家 “性善论”、道家 “无为” 论与批判 现代专制政治相结合。李大钊认为人“性”中包含着民 主政治因素，民众的衣食住行也不可能脱离现实政治 制度而存在。虽然历史型态下的孔子及其儒家文化已 经与时代精神渐行渐远, 尤其是儒家“名教”的社会教 化功能有约束人的创新思维的局限性, 但是 “孔孟亦 何尝责人以必牺牲其自我之权威, 而低首下心甘为其 傀儡也哉”。[7]这就说明孔孟之道中包含了也有尊重 人权和个人诉求的思想。 
不过，李大钊认为道家的“自然” “无为” 的政治 思想, 庄子积极向上的乐观主义人生哲学, 更加适应 现实政治的发展需要。

李大钊在《民彝与政治》一文中多次引用了老子 《道德经》的观点。如“彝亦训常, 《书·洪范》云: ‘彝 伦做叙。”彝伦者, 伦常也, 又与夷通用。”[8]李大钊 明确了 “彝”“常”的概念。“常” 可以理解为民众 “平 常”“简易”的日常生活状态; “民彝”理解为治理国家的 权威。二者统筹考量就是治理国家的要义在于关注民 众衣食住行, 以“无为而治”的思想出发点, 善待人民, 达到民众顺服的治理目标。

李大钊将人性的“善良”纳入了评判政治制度优 劣的标准，认为政治群体的“善良”与政治制度互为依 存。他说: “政治之良窊, 视乎其群之善良得否尽量以 著于政治; 而其群之善良得否尽量以著于政治, 则又 视乎其制度礼俗于涵育㸡导而外, 是否许人以径, 由 秉彝之诚, 圆融无碍, 而为彖决于事理得失利害之余 裕。”[9]因此，依天理的“民彝”与民主政治、现实政治 道路就具有了密切关联, 现代人在思考中国道路是就 要挖掘出被先哲们用 “宗彝” 屏蔽了“民彝”中的与时 俱进的现代民主政治诉求。

他深刻地揭示了在中国传统 “宗彝” 社会中, 统 治者及其代言人以 “宗彝” 压制 “民彝”, 维护统治者 以家天下的意志代替全体国民的意志的欺骗性。他认 为: 封建统治阶级以宗族为基本单位, 严重阻碍了新 时代自由、民主、现代政治的进步，造成了民族的依 赖性、行事的武断性、法制社会难以确立等历史流弊, 使社会变革举步维艰。在这种窃国大盗与乡愿恶奴隶 相互勾结的环境之下，国民个体追求自由民主权力就 被压制和弱化了。李大钊认为“民彝”的民主政治诉求 被屏蔽的根本原因是封建君主为了家天下的“一姓之 私”而“独尊”儒术, 控制意识形态。这种文化专制主义 政策会造成封建知识分子和广大民众依附统治者的 统治意志, 形成了“无我”的思维惯性。他们不得不盲 从往圣先贤的语录而无视社会现实政治改革的责任 和追求自我民主政治权利的本性。

李大钊创造性地解读了庄子的乐观主义的人生 哲学, 以扭转当时“民德沦丧”的颓废、厌世倾向, 引 导民众树立起民族的自尊、自觉意识树; 立起正确人 生观, 为振兴民族奋斗。他希望青年人继承中国传统 文化之中的积极向上, 开拓进取的思想, 秉持马克思 主义的革命英雄主义, “改变这随着他产生的误谬的 历史观, 人生观, 要回过头来顺着向未来发展的大自 然大实在的方面昂头迈进, 变逆退的为顺进的, 变静 止的为行动的”, [10]朝着革命的未来奋进。

李大钊在《青春》一文中对思想体系中的宇宙观 和人生观部分做了恰当补充, 倡导所有民族树立起青 春哲学的人生观。他通过唤起“青春”的力量实现中国 的民族“再生”，使他的理论进一步完备起来。他引用 庄子《逍遥游》中的经典名句“朝菌不知晦朔, 蟪蛄不 知春秋”“小知不如大知, 小年不如大年”, 论述了庄子
相对的宇宙观, 引出了他宇宙无尽、青春无尽、自我 无尽的无限宇宙观。这种“青春”的人生哲学，有利于 唤醒广大民众的“民”的自觉，树立起民族的自尊、自 觉意识, 为建设“青春之中华”奉献智慧。

李大钊还将中国传统文化中的变易观用于接受 西方社会进化论的历史文化依据, 并论述了宇宙世界 永恒发展变化的规律。

五四时期的先进知识分子陈独秀、李大钊、鲁迅 等人基本上都信奉过严复介绍的进化论, 并结合中国 传统文化的有机部分, 倡导社会变革, 推动思想解放 运动。李大钊认为: “大易之道, 太极生两仪, 两仪生 四象，四象生八卦。老氏之说，一生二，二生三，三 生万物。是知宇宙进化之理, 由浑而之画, 由一而之 杂, 乃为一定不变之律。” [11]李大钊相信如何国家和 民族与宇宙界的生命一样, 都经历了由青春到老年或 由老年到青春的进化过程, 社会历史新陈代谢是发展 的必然规律。他说: “由历史考之, 新兴之国族与陈腐 之国族遇，陈腐者必败; 朝气横溢之生命力与死灰沉 滞之生命力遇, 死灰沉滞者必败; 青春之国民与白首 之国民遇, 白首者必败, 此殆天演公例, 莫或能逃者 也。” ${ }^{[12]}$

可见, 李大钊以对孟子“性善论”新解释, 以道家 “无为” “自然” 和相对的宇宙观, 以传统变易观对接 西方社会进化论等思维方式, 升华了其传统文化观, 丰富和发展了他的中外哲学理论、社会政治理论和法 律规范, 形成了现代社会政治理论，使其理论完成了 由传统民本主义、民粹主义向现代民主主义理论的转 型。

\section{5. 李大钊基于批判儒家学说歧视劳动和劳 动人民的观点出发, 提出了劳动本位和劳动 者本位的思想}

李大钊从批判孔孟之道歧视劳动和劳动人民的 陈腐观点出发, 旗帜鲜明地倡导树立劳动无产者在世 界经济生产中的崇高地位, 提出了劳动本位和劳动者 本位的思想，并与其 “尊劳主义” 和 “平民政治” 思 想相结合, 为其接受马克思主义的无产阶级革命理论 打下了坚实的基础。

李大钊认为儒家思想及其纲常名教、伦理道德都 是建立在中国农业经济的基础上, 为封建君主专制主 义和封建大家族服务的主流意识形态, 已经不适应现 代经济组织和 “劳工神圣” 发展的需要。他说: “我们 可以晓得孔子主义 (就是中国人所谓纲常名教) 并不 是永久不变的真理。孔子或其他古人, 只是一代哲人, 决不是 “万世师表”。他的学说, 所以能在中国行了二 千余年, 全是因为中国的农业经济没有很大的变动, 他的学说适宜那样经济状况的原故。” [13]

李大钊认为: “从前的经济学, 是以资本为本位, 以资本家为本位。以后的经济学, 要以劳动为本位, 以劳动者为本位了。这正是个人主义向社会主义、人 
道主义过渡的时代。” [14]他视 “劳动” 和 “劳动者” 为 推动社会经济发展中的重要因素, 丰富和发展了其 “尊劳主义” 的思想。李大钊立足于 “劳动” 和 “劳 动者” 的认识, 对马克思主义关于经济基础决定上层 建筑的规律有了基本认识。他认为经济构造是全社会 基础架构, 社会的发展都必须依据经济结构的变化而 变化。因为, 经济制度是 “劳动” 和 “劳动者” 本位 的反映, 离开 “劳动” 和 “劳动者” 本位的经济制度 是没有基础的。这就表明, 离开 “劳动” 和 “劳动者” 本位的上层建筑就必须改变。

李大钊还提出了人民是推动社会发展的决定力 量的社会变革规律。李大钊认为: “俄国革命起于一 九一七年,惹起世人的注意,并非单是一国政治变更, 实在是世界的革命, 是平民阶级对资产阶级的战争。” [15]李大钊长期以来都有同情劳动无产者的情怀。他曾 经以北京最为贫困、劳累的人力车夫为例, 来说明中 国的平民阶级终日穷尽体力, 为社会服务, 为社会牺 牲, 获得十分微薄报酬来维系一家老弱生命的残酷现 状。

李大钊认为, 那种关注于如何处理好人民与统治 者关系的惯性思维已经不适应社会历史的发展。现代 “平民主义” 已经由 “属于人民、为人民、由于人民 的政治” 转变为 “属于人民、为人民、由于人民的执 行”。[16]这就意味着, 我们要实现 “平民主义', 不必 将关注的重点放在权利的获取, 应该重点探讨管理事 务的技术。因为依靠政治强权来统治人民违背了人民 的意志, 未来政府管理改良方向的重点必须立足于人 民的认同，代表人民的意志，依靠人民的力量, 获得 人民的支持。可见, 李大到接受马克思主义之后, 他 的民主政治理论完成了从中国传统民彝政治到平民 政治的改造和超越，抛弃了资产阶级的民主主义，从 而形成了无产阶级的民主主义。

\section{6. 结论}

李大钊对中国传统文化的态度反映了那个时代 先进的中国人对中国文化的既自信有批判的态度; 反 映了早期马克思主义者对待西方文化的合理因素的 接纳态度; 赋予中国传统文化新的含义并推动了传统 文化的现代性改造, 深刻地揭示出了传统文化现代化 的一般规律。

第一, 李大钊强调传统文化的现代化必须坚定民 族文化自信。他认为东西方两种文明各有长短, 不宜 武断地进行简单的比对。他主张新旧融合、东西融合, 共同为人类文明发展和社会的文明进步奉献智慧。他 相信中国传统文化中的积极因素有助于中国人接受 外来先进文化, 并在俄国十月社会主义革命后成功之 后, 积极地运用中国传统文化接纳了马克思主义。他 社会历史发展规律的角度将儒家大同社会理想与共 产主义远大理想对比分析, 得出了两者最终社会理想 必然通向世界大同。他描绘的自由、平等、相爱助的 “至高理想”就是 “在使人间一切关系都脱去力的关
系, 而纯为爱的关系, 使人间一切生活全不是争的生 活，而纯是爱的生活”。[17]

第二, 李大钊提出了在传统文化自有的框架内进 行批判继承的原则。一是他倡导中国人必须辩证地看 待民族传统文化。他认为不能以当代的是非标准来衡 量传统文化,对待传统文化要历史地看, 发展地看, 辩 证地看。他认为即使孔子生在现代社会, 也有可能大 力倡导民权自由之大义。他还提出了用辩证思维区分 反专制与反孔教的正确原则。他特别说明道: “余之 掊击孔子, 非掊击孔子之本身, 乃掊击孔子为历代君 主所雕塑之偶像的权威也; 非掊击孔子, 乃掊击专制 政治之灵魂也。” ${ }^{[18]}$ 二是他明确提出了对待孔子之道 的一分为二的取舍态度。他认为要接受孔子之道中合 于真理的部分, 抛弃其与真理相背离的部分。三是他 提倡吸收多种传统文化来优化现代政治学说的结构。 李大钊重视吸收诸子百家学说来对接现代政治学说。 如他在《民彝与政治》一文中多次引用了老子《道德 经》的观点来阐发他民主政治观。

第三，李大钊奠定了中国化的马克思主义辩证唯 物主义和历史唯物主义的基础。他运用马克思主义的 历史唯物主义旗帜鲜明地批驳了 “ 孔孟之徒, 言必称 尧、舜”的崇古史观, 倡导用时代精神随时检验历史。 他认为: “一时代有一时代比较进步的历史观, 一时 代有一时代比较进步的知识, 史观与知识不断的进步, 人们对于历史事实的解喻自然要不断地变动。" [19]他 还特别强调要根据新史观、新史料随时改作一切历史, 以揭示历史的智慧为现实服务。

诚然，李大钊的这些文化自觉、文化理性和文化 改造原则是基于中华民族创造了辉煌灿烂的中华文 明，这种五千多年绵延不断的文明使得中华民族历史 悠久, 为人类社会进步分享了智慧, 成为世界上伟大 的民族的雄厚根基。这种雄厚根基让一个近代经济技 术落后的中国接受了马克思主义, 产生了中国共产党 领导着中国人民不断创造从站起来、富起来到强起来 的奇迹。“回顾历史, 支撑我们这个古老民族走到今 天的, 支撑五千多年中华文明延绵至今的, 是根植于 中华民族血脉深处的文化基因”。[20]今天我们总结以 李大钊为杰出代表的革命先辈对待传统文化的宝贵 智慧和思想遗产, 必将会彰显中国特色社会主义的道 路自信、理论自信、制度自信、文化自信。

\section{项目基金}

本文为 2018 年教育部示范优秀教学科研团队 《早期马克思主义对中华优秀传统文化的认识与运 用研究》（18JDSZK075）的阶段性成果之一。

\section{REFERENCES}

[1] Li Dazhao Research Association of China. (2013) Complete works of Li Dazhao: Volume 5.People's publishing house, Beijing.pp.297. 
[2] Li Dazhao Research Association of China. (2013) Complete works of Li Dazhao: Volume 1.People's publishing house, Beijing.pp.426.

[3] Li Dazhao Research Association of China. (2013) Complete works of Li Dazhao: Volume 1.People's publishing house, Beijing.pp.269.

[4] Li Dazhao Research Association of China. (2013) Complete works of Li Dazhao: Volume 1.People's publishing house, Beijing.pp.267.

[5] Li Dazhao Research Association of China. (2013) Complete works of Li Dazhao: Volume 1.People's publishing house, Beijing.pp.269.

[6] Li Dazhao Research Association of China. (2013) Complete works of Li Dazhao: Volume 1.People's publishing house, Beijing.pp.271.

[7] Li Dazhao Research Association of China. (2013) Complete works of Li Dazhao: Volume 1.People's publishing house, Beijing.pp.274.

[8] Li Dazhao Research Association of China. (2013) Complete works of Li Dazhao: Volume 1.People's publishing house, Beijing.pp.269.

[9] Li Dazhao Research Association of China. (2013) Complete works of Li Dazhao: Volume 1.People's publishing house, Beijing.pp.272-273.

[10] Li Dazhao Research Association of China. (2013) Complete works of Li Dazhao: Volume 4.People's publishing house, Beijing.pp.453 .

[11] 1Li Dazhao Research Association of China. (2013) Complete works of Li Dazhao: Volume 1.People's publishing house, Beijing.pp.420.

[12] Li Dazhao Research Association of China. (2013) Complete works of Li Dazhao: Volume 1.People's publishing house, Beijing.pp.312.

[13] Li Dazhao Research Association of China. (2013)Complete works of Li Dazhao: Volume 3.People's publishing house, Beijing.pp.191.

[14] Li Dazhao Research Association of China. (2013)Complete works of Li Dazhao: Volume 3.People's publishing house, Beijing.pp.4.

[15] Li Dazhao Research Association of China. (2013)Complete works of Li Dazhao: Volume 3.People's publishing house, Beijing.pp.361.

[16] Li Dazhao Research Association of China. (2013) Complete works of Li Dazhao: Volume 4.People's publishing house, Beijing.pp.147.

[17] Li Dazhao Research Association of China. (2013)Complete works of Li Dazhao: Volume 3.People's publishing house, Beijing.pp.214.
[18] Li Dazhao Research Association of China. (2013) Complete works of Li Dazhao: Volume 1.People's publishing house, Beijing.pp.429.

[19] Li Dazhao Research Association of China. (2013) Complete works of Li Dazhao: Volume 4.People's publishing house, Beijing.pp.523.

[20] Xi,J.P.(2019) Work together to build a better world (December 1, 2017).Tn:the party history and documentation research office of the CPC Central Committee,(Eds),Nineteen important documents selected from China (Part one). Central Literature press, Beijing.pp.109. 